\title{
PREVALÊNCIA DE SOBREPESO E OBESIDADE NA SÍNDROME DE DOWN Pôster
}

Autores deste trabalho:

Mariana Morais Olimpio: Acadêmico do Curso de Medicina da Faculdade de Medicina União dos Grandes Lagos - UNILAGO / São José do Rio Preto (SP)

Wanderson Souza Martins: Acadêmico do Curso de Medicina da Faculdade de Medicina União dos Grandes Lagos - UNILAGO / São José do Rio Preto (SP)

Joāo Lucas Morais Olimpio: Acadêmico do Curso da Faceres

Priscila Donda: Professora do Curso de Medicina da Faculdade de Medicina Uni\&\#257; o dos Grandes Lagos - UNILAGO / São José do Rio Preto (SP)

Área do Trabalho: Pediatria

Data da submissão: 14/08/2018 às 23:04

\section{Justificativa}

Analisar a obesidade em portadores de Síndrome de DowN

\section{Objetivo(s)}

O objetivo é verificar a prevalência de sobrepeso e obesidade em portadores da síndrome de Down residentes nos municípios de Mirassol (SP).

\section{Método(s)}

Trata-se de estudo corte-transversal, realizado durante o mês de Junho de 2017. A pesquisa foi submetida e aprovada pelo Comitê de Ética e Pesquisa da UNILAGO no 2.556.227 . Para coleta dos dados utilizamos uma ficha de dados elaborada pela pesquisadora, que constava os dados, sexo, idade, prática ou não de atividade física, peso, estatura, tabela de Escore Z e tabela de Percentil e cálculo de Índice de massa corpórea (IMC) para adultos.

\section{Resultado(s)}

Avaliou-se 15 pessoas no total, sendo 10 adultos, $3(20,0 \%)$ do sexo feminino e 7 do sexo masculino (46,7\%). E 5 crianças sendo $2(13,3 \%)$ do sexo feminino e $3(20,0 \%)$ do sexo masculino. Apresentados os dados na tabela 1 a seguir, divido entre adultos e crianças. Estudos têm demonstrado que a prevalência de sobrepeso e obesidade sofre incremento com o avanço da idade em pessoas com SD, tornando-se fundamental a prevenção da obesidade nessa população para diminuir os riscos de comorbidades.

Analisando os resultados através estudo corte-transversal, podemos verificar que no presente estudo, há um grande numero de indivíduos obesos (70\%), sendo que a escola mostrou ser local adequado para a detecção precoce do excesso de peso na criança com um custo praticável baixo, podendo assim auxiliar os órgãos de saúde pública na adoção de medidas preventivas, tratamento e monitoramento nutricional das crianças, com reflexos diretos sobre a prevalência das doenças crônicas e obesidade na idade adulta.

Os achados deste estudo reforçam a ideia de que o excesso de peso na população é 
um problema de saúde pública que se inicia precocemente na infância e tende a se perpetuar na idade adulta, influenciando de maneira direta e imediata a qualidade de vida destas populações.

\section{Conclusão (ões)}

Comparando-se as medidas de peso e altura aferidas com as medidas estimadas, conclui-se que grau de obesidade desta população total entre adultos e crianças é $70 \%$ obesos, $30 \%$ sobrepeso e $20 \%$ normal, visando que é um índice altíssimo de obesos. 